Sādhanā Vol. 36, Part 1, February 2011, pp. 109-123. @ Indian Academy of Sciences

\title{
Application of response surface methodology for determining cutting force model in turning hardened AISI H11 hot work tool steel
}

\author{
B FNIDES ${ }^{1, *}$, M A YALLESE $^{1}$, T MABROUKI $^{2}$ and J-F RIGAL ${ }^{2}$ \\ ${ }^{1}$ Mechanics and Structures Laboratory (LMS), Department of Mechanical \\ Engineering, University 08 Mai 1945, P. O. Box 401, Guelma 24000, Algeria \\ ${ }^{2}$ Université de Lyon, CNRS, INSA - Lyon, LaMCoS, UMR5259, F69621, France \\ e-mail: fbrahim@yahoo.fr; jean-francois.rigal@insa-lyon.fr
}

MS received 20 January 2010; revised 29 June 2010; accepted 15 October 2010

\begin{abstract}
This experimental study is conducted to determine statistical models of cutting forces in hard turning of AISI H11 hot work tool steel ( $\sim 50 \mathrm{HRC}$ ). This steel is free from tungsten on $\mathrm{Cr}-\mathrm{Mo}-\mathrm{V}$ basis, insensitive to temperature changes and having a high wear resistance. It is employed for the manufacture of highly stressed diecasting moulds and inserts with high tool life expectancy, plastic moulds subject to high stress, helicopter rotor blades and forging dies.

The workpiece is machined by a mixed ceramic tool (insert CC650 of chemical composition $70 \% \mathrm{Al}_{2} \mathrm{O}_{3}+30 \% \mathrm{TiC}$ ) under dry conditions. Based on $3^{3}$ full factorial design, a total of 27 tests were carried out. The range of each parameter is set at three different levels, namely low, medium and high. Mathematical models were deduced by software Minitab (multiple linear regression and response surface methodology) in order to express the influence degree of the main cutting variables such as cutting speed, feed rate and depth of cut on cutting force components. These models would be helpful in selecting cutting variables for optimization of hard cutting process.

The results indicate that the depth of cut is the dominant factor affecting cutting force components. The feed rate influences tangential cutting force more than radial and axial forces. The cutting speed affects radial force more than tangential and axial forces.
\end{abstract}

Keywords. Hard turning; ceramic tool; AISI H11; cutting force; ANOVA; RSM.

$\overline{\text { *For correspondence }}$ 


\section{Introduction}

Hard turning is a cutting process defined as turning materials with hardness higher than 45 HRC under appropriate cutting tools and high cutting speed. Machining of hard steel using advanced tool materials, such as cubic boron nitride and mixed ceramic, has more advantages than grinding or polishing, such as short cycle time, process flexibility, compatible surface roughness, higher material removal rate and less environment problems without the use of cutting fluid. This process has become a normal practice in industry because it increases productivity and reduces energy consumption (Fnides et al 2008; Bouacha et al 2010; Fnides et al 2009).

Alumina $\left(\mathrm{Al}_{2} \mathrm{O}_{3}\right)$ based ceramics are considered to be the most suitable tool materials, among others, for machining hardened steels because of their high hot hardness, wear resistance and chemical inertness (Dewes \& Aspinwall 1997).

Qamar (2009) has studied mechanical testing of H11 samples. His results revealed that with increasing temperatures: (a) hardness increases to a maximum and then gradually decreases; (b) impact toughness decreases to a minimum and then increases; (c) yield strength decreases, then increases, and then increases again; (d) ultimate strength increases to a maximum and then steadily decreases; and (e) ductility (\% elongation) gradually decreases till $600^{\circ} \mathrm{C}$, and then increases rather sharply.

Cutting force is classified among the most important technological parameter to control in machining process. It is the background for the evaluation of the necessary power machining (choice of the electric motor). It is also used for dimensioning of machine tool components and the tool body. It influences machining system stability. In hard turning, cutting forces have been found to be influenced by a number of factors such as depth of cut, feed rate, cutting speed, cutting time, workpiece hardness, etc. (Ozel et al 2005).

Strafford \& Audy (1997), Luo et al (1999) have investigated the relationship between hardness and cutting forces during turning AISI 4340 steel hardened from 29 to 57 HRC using mixed alumina tools. The results suggest that an increase of $48 \%$ in hardness leads to an increase in cutting forces from 30 to $80 \%$. It is reported that for work material hardness values between 30 and $50 \mathrm{HRC}$, continuous chips were formed and the cutting force components were reduced. However, when the workpiece hardness increased above $50 \mathrm{HRC}$, segmented chips were observed and the cutting force showed a sudden elevation.

In machining AISI D2 steel hardened at $62 \mathrm{HRC}$ with $\mathrm{CBN}$ tools, the relationship between forces and cutting regime could be represented by power function type equations (Arsecularatne et al 2006).

Yallese et al (2009) confirmed that in hard machining of hardened bearing steel using cubic boron nitride tool, the radial force is dominating especially when machining is within the limit of tool nose radius. Such finding is in contradiction with what is known from conventional turning as radial force is about 30 to $50 \%$ from the tangential cutting force. Consequently, the radial force cannot be neglected in characterizing static and dynamic behaviours of such machining system.

The aim of the present study is, thus, to develop a statistical model for using the main cutting parameters such as cutting speed, feed rate and depth of cut on AISI H11 hardened steel. Machining tests were carried out under different conditions with mixed ceramic cutting tool. The model predicting equations for cutting forces were developed. To calculate constants and coefficients of these models, the software Minitab characterized by analysis of variance (ANOVA), multiple linear regression and response surface methodology (RSM) was exploited. 


\section{Experimental procedure}

The material used for experiments is AISI H11, hot work tool steel which is popularly used in hot form pressing. Its resistance to high temperature and its ability for polishing enable it to answer the most severe requests in hot dieing, helicopter rotor blades and moulds under pressure. Its chemical composition is given in table 1 .

The workpiece is hardened to $50 \mathrm{HRC}$. Its hardness was measured by a digital durometer DM2D. It is of $72 \mathrm{~mm}$ in diameter and it is machined under dry conditions. Short duration tests were performed (machining length is $18 \mathrm{~mm}$ ). Each test is realized with a new cutting edge.

The lathe used for machining operations is TOS TRENCIN; model SN40C, spindle power 6.6 KW. The cutting forces were measured in real time with a Kistler three component dynamometer model $9257 \mathrm{~B}$ linked via a multichannel charge amplifier (type $5011 \mathrm{~B}$ ) to high impedance cable. Illustration of measured forces is given in figure 1.

The cutting insert used is a mixed ceramic (CC650), removable, of square form with eight cutting edges and having designation SNGA 120408 T01020. Its nose radius, $r_{\varepsilon}=0.8 \mathrm{~mm}$. The insert is mounted on a commercial toolholder of designation PSBNR2525M12 with the geometry of active part characterized by the following angles: $\chi=75^{\circ} ; \alpha=6^{\circ} ; \gamma=-6^{\circ}$; $\lambda=-6^{\circ}$ (SANDVIK 2009).

Three levels were defined for each cutting variable as given in table 2 . The variable levels were chosen within the intervals recommended by the cutting tool manufacturer. Three cutting variables at three levels led to a total of 27 tests. The factors to be studied and the attribution of the respective levels are indicated in table 3. The first column of this table was assigned to the cutting speed $(V c)$, the second to the feed rate $(f)$ and the fifth to the depth of cut $(a p)$. The remaining columns were referred to the interactions.

Since there are a large number of variables controlling the cutting process, some mathematical models are required to represent this process. However, these models have to be developed using only the significant parameters influencing the process rather than including all the parameters. In order to achieve this, statistical analysis of the experimental results will have to be processed using the analysis of variance (ANOVA). The latter is a computational technique that enables the estimation of the relative contributions of each of the control factors to the overall

Table 1. Chemical composition of grade AISI H11.

\begin{tabular}{lc}
\hline Composition & (Wt. \%) \\
\hline $\mathrm{C}$ & 0.35 \\
$\mathrm{Cr}$ & 5.26 \\
$\mathrm{Mo}$ & 1.19 \\
$\mathrm{~V}$ & 0.5 \\
$\mathrm{Si}$ & 1.01 \\
$\mathrm{Mn}$ & 0.32 \\
$\mathrm{~S}$ & 0.002 \\
$\mathrm{P}$ & 0.016 \\
Other components & 1.042 \\
Fe & 90.31 \\
\hline
\end{tabular}



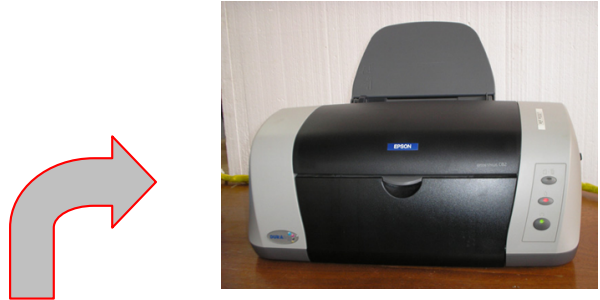

Printer

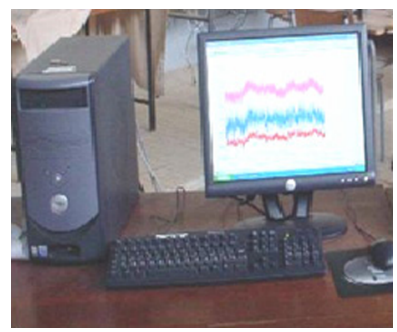

Software (Dynoware)

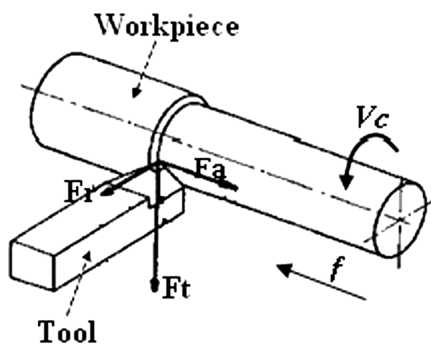

Cutting force components

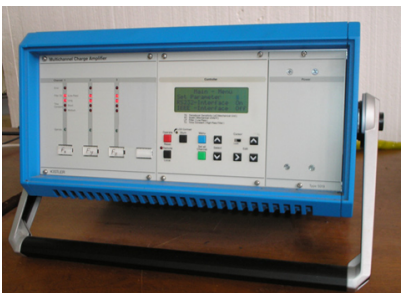

Multichannel charge amplifier (type 5011B)
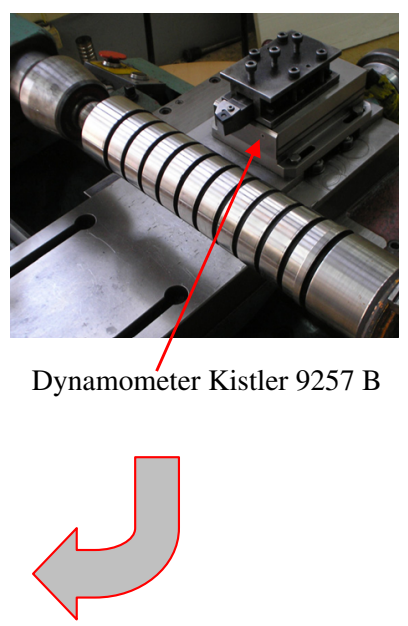

Figure 1. Illustration of measured forces.

measured response. In this work, only the significant parameters will be used to develop mathematical models using response surface methodology (RSM). RSM is a collection of mathematical and statistical techniques that are useful for the modelling and analysis of problems in which response of interest is influenced by several variables and the objective is to optimize the response (Paulo Davim \& Figueira 2007; Noordin et al 2004; Gaitonde et al 2009; Sing \& Rao 2007; Palanikumar et al 2008; Chiang 2008; Abhang \& Hameedullah 2010).

Table 2. Assignment of the levels to the variables.

\begin{tabular}{lccc}
\hline Level & $V c, \mathrm{~m} / \mathrm{min}$ & $f, \mathrm{~mm} / \mathrm{rev}$ & $a p, \mathrm{~mm}$ \\
\hline-1 (low) & 90 & 0.08 & 0.15 \\
0 (medium) & 120 & 0.12 & 0.30 \\
+1 (high) & 180 & 0.16 & 0.45 \\
\hline
\end{tabular}


Table 3. Plan of experiments.

\begin{tabular}{crrrrrrrrrrrrr}
\hline Test & 1 & 2 & 3 & 4 & 5 & 6 & 7 & 8 & 9 & 10 & 11 & 12 & 13 \\
\hline 1 & -1 & -1 & -1 & -1 & -1 & -1 & -1 & -1 & -1 & -1 & -1 & -1 & -1 \\
2 & -1 & -1 & -1 & -1 & 0 & 0 & 0 & 0 & 0 & 0 & 0 & 0 & 0 \\
3 & -1 & -1 & -1 & -1 & +1 & +1 & +1 & +1 & +1 & +1 & +1 & +1 & +1 \\
4 & -1 & 0 & 0 & 0 & -1 & -1 & -1 & 0 & 0 & 0 & +1 & +1 & +1 \\
5 & -1 & 0 & 0 & 0 & 0 & 0 & 0 & +1 & +1 & +1 & -1 & -1 & -1 \\
6 & -1 & 0 & 0 & 0 & +1 & +1 & +1 & -1 & -1 & -1 & 0 & 0 & 0 \\
7 & -1 & +1 & +1 & +1 & -1 & -1 & -1 & +1 & +1 & +1 & 0 & 0 & 0 \\
8 & -1 & +1 & +1 & +1 & 0 & 0 & 0 & -1 & -1 & -1 & +1 & +1 & +1 \\
9 & -1 & +1 & +1 & +1 & +1 & +1 & +1 & 0 & 0 & 0 & -1 & -1 & -1 \\
10 & 0 & -1 & 0 & +1 & -1 & 0 & +1 & -1 & 0 & +1 & -1 & 0 & +1 \\
11 & 0 & -1 & 0 & +1 & 0 & +1 & -1 & 0 & +1 & -1 & 0 & +1 & -1 \\
12 & 0 & -1 & 0 & +1 & +1 & -1 & 0 & +1 & -1 & 0 & +1 & -1 & 0 \\
13 & 0 & 0 & +1 & -1 & -1 & 0 & +1 & 0 & +1 & -1 & +1 & -1 & 0 \\
14 & 0 & 0 & +1 & -1 & 0 & +1 & -1 & +1 & -1 & 0 & -1 & 0 & +1 \\
15 & 0 & 0 & +1 & -1 & +1 & -1 & 0 & -1 & 0 & +1 & 0 & +1 & -1 \\
16 & 0 & +1 & -1 & 0 & -1 & 0 & +1 & +1 & -1 & 0 & 0 & +1 & -1 \\
17 & 0 & +1 & -1 & 0 & 0 & +1 & -1 & -1 & 0 & +1 & +1 & -1 & 0 \\
18 & 0 & +1 & -1 & 0 & +1 & -1 & 0 & 0 & +1 & -1 & -1 & 0 & +1 \\
19 & +1 & -1 & +1 & 0 & -1 & +1 & 0 & -1 & +1 & 0 & -1 & +1 & 0 \\
20 & +1 & -1 & +1 & 0 & 0 & -1 & +1 & 0 & -1 & +1 & 0 & -1 & +1 \\
21 & +1 & -1 & +1 & 0 & +1 & 0 & -1 & +1 & 0 & -1 & +1 & 0 & -1 \\
22 & +1 & 0 & -1 & +1 & -1 & +1 & 0 & 0 & -1 & +1 & +1 & 0 & -1 \\
23 & +1 & 0 & -1 & +1 & 0 & -1 & +1 & +1 & 0 & -1 & -1 & +1 & 0 \\
24 & +1 & 0 & -1 & +1 & +1 & 0 & -1 & -1 & +1 & 0 & 0 & -1 & +1 \\
25 & +1 & +1 & 0 & -1 & -1 & +1 & 0 & +1 & 0 & -1 & 0 & -1 & +1 \\
26 & +1 & +1 & 0 & -1 & 0 & -1 & +1 & -1 & +1 & 0 & +1 & 0 & -1 \\
27 & +1 & +1 & 0 & -1 & +1 & 0 & -1 & 0 & -1 & +1 & -1 & +1 & 0 \\
\hline
\end{tabular}

\section{Results and discussion}

Table 4 presents experimental results of cutting force components ( $F a, F r$ and $F t$ ) for various combinations of cutting regime parameters (cutting speed, feed rate and depth of cut) according to $3^{3}$ full factorial design. The results indicate that the lower cutting forces were registered at the higher cutting speeds. This can be related to the temperature increase in cutting zone and leads to the drop of the workpiece yield strength and chip thickness. The results also show that cutting forces increase with increasing feed rate and depth of cut because chip thickness becomes significant what causes the growth of the volume of deformed metal. Consequently, enormous forces to cut the chip are required. Minimal values of cutting forces were obtained at $V c=180 \mathrm{~m} / \mathrm{min}, f=0.08 \mathrm{~mm} / \mathrm{rev}$ and $a p=0.15 \mathrm{~mm}$ (test number 19). That means increasing of cutting speed with lowest feed rate and depth of cut leads to decreasing of cutting force components.

Maximal values of cutting force components $(F a, F r$ and $F t$ ) were registered at $V c=90 \mathrm{~m} / \mathrm{min}$ and $f=0.16 \mathrm{~mm} / \mathrm{rev}$ and $a p=0.45 \mathrm{~mm}$ (test number 9 ). In order to achieve better machining system stability, the highest level of cutting speed, $180 \mathrm{~m} / \mathrm{min}$, the lowest level of feed rate, $0.08 \mathrm{~mm} / \mathrm{rev}$, the lowest level of depth of cut, $0.15 \mathrm{~mm}$, should be recommended. 
Table 4. Design layout and experimental results for cutting force components.

\begin{tabular}{|c|c|c|c|c|c|c|c|c|c|}
\hline \multirow[t]{2}{*}{ Tests $\mathrm{N}^{\circ}$} & \multicolumn{3}{|c|}{ Coded factors } & \multicolumn{3}{|c|}{ Actual factors } & \multicolumn{3}{|c|}{ Performance measures } \\
\hline & $X_{1}$ & $X_{2}$ & $X_{3}$ & $V c, \mathrm{~m} / \mathrm{min}$ & $f, \mathrm{~mm} / \mathrm{rev}$ & $a p, \mathrm{~mm}$ & $F a, \mathrm{~N}$ & $F r, \mathrm{~N}$ & $F t, \mathrm{~N}$ \\
\hline 1 & -1 & -1 & -1 & 90 & 0.08 & 0.15 & 30.25 & 89.67 & 70.67 \\
\hline 2 & -1 & -1 & 0 & 90 & 0.08 & 0.30 & 66.75 & 139.24 & 130.84 \\
\hline 3 & -1 & -1 & +1 & 90 & 0.08 & 0.45 & 130.72 & 182.79 & 176.33 \\
\hline 4 & -1 & 0 & -1 & 90 & 0.12 & 0.15 & 32.71 & 100.45 & 80.40 \\
\hline 5 & -1 & 0 & 0 & 90 & 0.12 & 0.30 & 85.64 & 157.54 & 146.43 \\
\hline 6 & -1 & 0 & +1 & 90 & 0.12 & 0.45 & 138.19 & 197.73 & 221.68 \\
\hline 7 & -1 & +1 & -1 & 90 & 0.16 & 0.15 & 35.03 & 115.96 & 107.11 \\
\hline 8 & -1 & +1 & 0 & 90 & 0.16 & 0.30 & 90.32 & 174.44 & 176.97 \\
\hline 9 & -1 & +1 & +1 & 90 & 0.16 & 0.45 & 142.63 & 217.70 & 266.34 \\
\hline 10 & 0 & -1 & -1 & 120 & 0.08 & 0.15 & 29.34 & 83.21 & 58.59 \\
\hline 11 & 0 & -1 & 0 & 120 & 0.08 & 0.30 & 66.27 & 134.47 & 124.92 \\
\hline 12 & 0 & -1 & +1 & 120 & 0.08 & 0.45 & 106.26 & 162.77 & 158.60 \\
\hline 13 & 0 & 0 & -1 & 120 & 0.12 & 0.15 & 32.69 & 93.22 & 79.61 \\
\hline 14 & 0 & 0 & 0 & 120 & 0.12 & 0.30 & 74.64 & 142.64 & 136.18 \\
\hline 15 & 0 & 0 & +1 & 120 & 0.12 & 0.45 & 122.67 & 180.75 & 209.37 \\
\hline 16 & 0 & +1 & -1 & 120 & 0.16 & 0.15 & 34.13 & 104.96 & 96.02 \\
\hline 17 & 0 & +1 & 0 & 120 & 0.16 & 0.30 & 76.13 & 161.92 & 169.61 \\
\hline 18 & 0 & +1 & +1 & 120 & 0.16 & 0.45 & 132.60 & 211.49 & 238.10 \\
\hline 19 & +1 & -1 & -1 & 180 & 0.08 & 0.15 & 27.68 & 70.57 & 50.58 \\
\hline 20 & +1 & -1 & 0 & 180 & 0.08 & 0.30 & 64.05 & 120.92 & 105.85 \\
\hline 21 & +1 & -1 & +1 & 180 & 0.08 & 0.45 & 101.46 & 143.15 & 152.45 \\
\hline 22 & +1 & 0 & -1 & 180 & 0.12 & 0.15 & 29.24 & 92.30 & 64.74 \\
\hline 23 & +1 & 0 & 0 & 180 & 0.12 & 0.30 & 66.33 & 127.26 & 117.06 \\
\hline 24 & +1 & 0 & +1 & 180 & 0.12 & 0.45 & 117.09 & 169.37 & 172.71 \\
\hline 25 & +1 & +1 & -1 & 180 & 0.16 & 0.15 & 33.26 & 101.77 & 85.37 \\
\hline 26 & +1 & +1 & 0 & 180 & 0.16 & 0.30 & 70.27 & 147.58 & 168.65 \\
\hline 27 & +1 & +1 & +1 & 180 & 0.16 & 0.45 & 117.09 & 179.62 & 234.16 \\
\hline
\end{tabular}

\subsection{ANOVA for $\mathrm{Fa}$}

The results of analysis of variance (ANOVA) for axial force $F a$ are shown in table 5. This table also shows the degrees of freedom (DF), sum of squares (SS), mean squares (MS), F-values (F-VAL.) and probability (P-VAL.) in addition to the percentage contribution (Contr. \%) of each

Table 5. ANOVA for $F a$.

\begin{tabular}{lrrrrrr}
\hline Source & DF & \multicolumn{1}{c}{ SS } & \multicolumn{1}{c}{ MS } & F-VAL. & P-VAL. & Contr. \% \\
\hline$V c$ & 2 & 894.6 & 447.3 & 22.87 & $<0.001$ & 2.23 \\
$f$ & 2 & 692.3 & 346.1 & 17.70 & 0.001 & 1.72 \\
$a p$ & 2 & 37852.3 & 18926.2 & 967.82 & $<0.001$ & 94.22 \\
$V c \times f$ & 4 & 20.4 & 5.1 & 0.26 & 0.895 & 0.05 \\
$V c \times a p$ & 4 & 408.6 & 102.1 & 5.22 & 0.023 & 1.02 \\
$f \times a p$ & 4 & 147.9 & 37.0 & 1.89 & 0.206 & 0.37 \\
Error & 8 & 156.4 & 19.6 & & & 0.39 \\
Total & 26 & 40172.6 & & & & 100 \\
\hline
\end{tabular}


factor and different interactions. A low P-value $(\leq 0.05)$ indicates statistical significance for the source on the corresponding response (i.e., $\alpha=0.05$, or $95 \%$ confidence level), this indicates that the obtained models are considered to be statistically significant, which is desirable; as it demonstrates that the terms in the model have a significant effect on the response. The other important coefficient, $R^{2}$, which is called coefficient of determination in the resulting ANOVA tables, is defined as the ratio of the explained variation to the total variation and is a measure of the fit degree. When $R^{2}$ approaches to unity, it indicates a good correlation between the experimental and the predicted values.

It is clear from the results of ANOVA that the depth of cut affects $F a$ in a considerable way. Its contribution is $94.22 \%$. The second factor influencing $\mathrm{Fa}$ is cutting speed. Its contribution is $2.23 \%$. For feed rate, its effect is less important and its contribution is $1.72 \%$. The interaction $V c \times a p$ is significant. Its contribution is $1.02 \%$. The interactions $V c \times f$, and $f \times a p$ are not significant and their contributions are 0.05 and $0.37 \%$, respectively.

To understand the hard turning process in terms of axial force $F a$, mathematical model was developed using multiple linear regression method. However, this model is built using only the main cutting variables (cutting speed, feed rate and depth of cut) and their significant interactions. Fa model is given by equation (1). Its coefficient of correlation $R^{2}$ is $98.2 \%$.

$$
F a=-44.85+0.09 V c+150.94 f+405.84 a p-0.77 V c \times a p .
$$

\subsection{Effect graphs of the main cutting regime on $\mathrm{Fa}$}

Figure 2 gives the main factor plots for $F a$. Axial force $F a$ appears to be a decreasing function of $V c$. This figure also indicates that $F a$ is an almost linear increasing function of $a p$. But the feed rate $f$ has a little effect on $F a$.

\subsection{D Surface plots of Fa}

3D Surface plots of $F a$ vs. different combinations of cutting regime elements are shown in figures 3, 4 and 5. These figures were obtained using response surface methodology (RSM) according to their mathematical models.

\subsection{ANOVA for $\mathrm{Fr}$}

Table 6 presents ANOVA results for $F r$. It can be seen that the depth of cut is the most important factor affecting radial force $\mathrm{Fr}$. Its contribution is $81.14 \%$. The second factor influencing $\mathrm{Fr}$

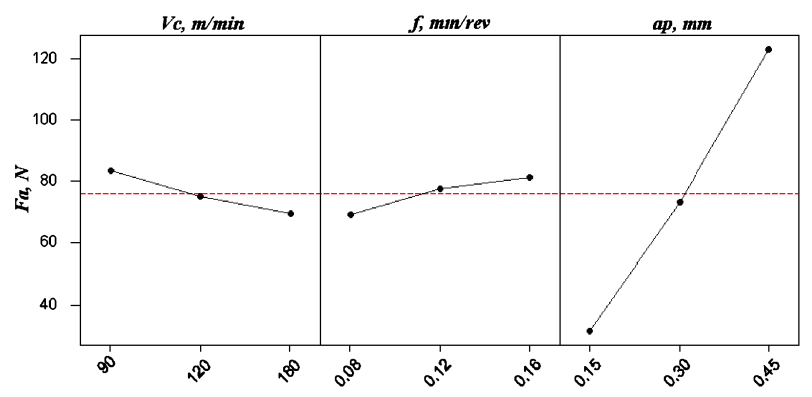

Figure 2. Graphs of the main cutting variables effects on $F a$. 


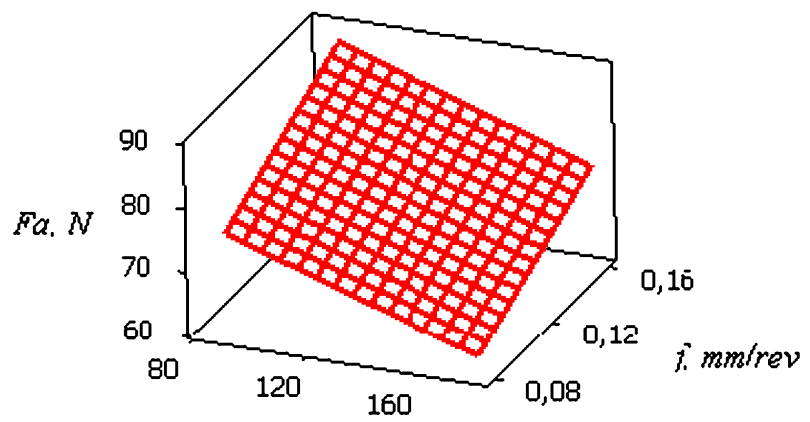

VC. $\operatorname{mimin}$

Figure 3. 3D Surface plot of $F a$ vs. $V c$ and $f$.

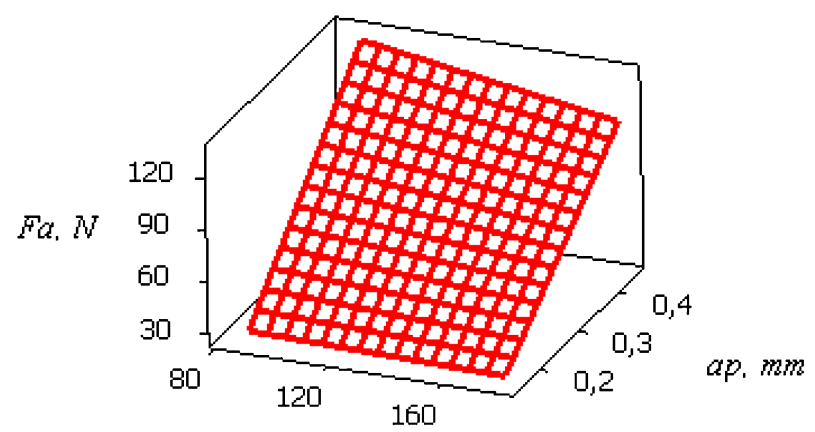

VC. $\mathrm{m} / \mathrm{min}$

Figure 4. 3D Surface plot of $F a$ vs. $V c$ and $a p$.

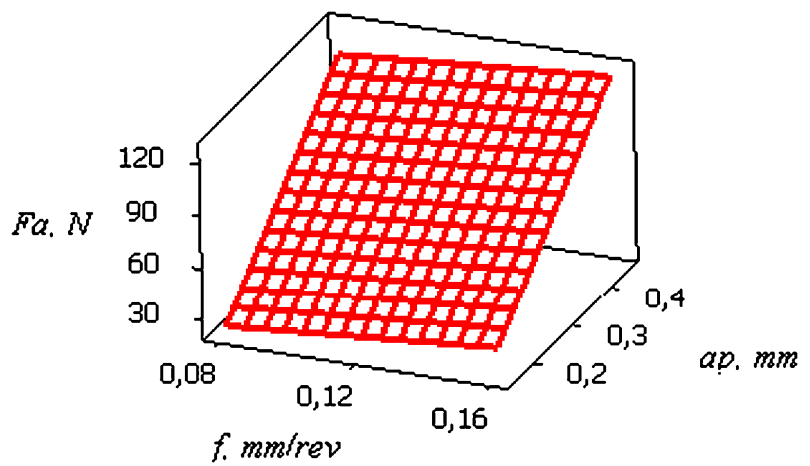

Figure 5. 3D Surface plot of $F a$ vs. $f$ and $a p$. 
Table 6. ANOVA for $F r$.

\begin{tabular}{lrrrrrr}
\hline Source & DF & \multicolumn{1}{c}{ SS } & \multicolumn{1}{c}{ MS } & F-VAL. & P-VAL. & Contr. \% \\
\hline$V c$ & 2 & 2771.9 & 1385.9 & 61.69 & $<0.001$ & 6.39 \\
$f$ & 2 & 4636.0 & 2318.0 & 103.18 & $<0.001$ & 10.69 \\
$a p$ & 2 & 35201.9 & 17601.0 & 783.45 & $<0.001$ & 81.14 \\
$V c \times f$ & 4 & 45.5 & 11.4 & 0.51 & 0.733 & 0.10 \\
$V c \times a p$ & 4 & 370.7 & 92.7 & 4.12 & 0.042 & 0.85 \\
$f \times a p$ & 4 & 177.1 & 44.3 & 1.97 & 0.192 & 0.41 \\
Error & 8 & 179.7 & 22.5 & & & 0.42 \\
Total & 26 & 43382.8 & & & & 100 \\
\hline
\end{tabular}

is feed rate. Its contribution is $10.69 \%$. For the cutting speed, its contribution is $6.39 \%$. The interaction $V c \times a p$ is significant. Its contribution is $0.85 \%$. The interactions $V c \times f$ and $f \times a p$ are not significant and their contributions are 0.10 and $0.41 \%$, respectively. $\mathrm{Fr}$ model is given by equation (2). Its coefficient of correlation $R^{2}$ is $98.1 \%$.

$$
F r=8.087-0.027 V c+400.903 f+398.584 a p-0.806 V c \times a p .
$$

\subsection{Effect graphs of the main cutting regime on $\mathrm{Fr}$}

Figure 6 shows the main factor plots for $F r$. Radial force $F r$ appears to be a decreasing function of $V c$. This figure also indicates that $F r$ is an almost linear increasing function of ap. But feed rate $f$ has a little effect on $F r$.

\subsection{D Surface plots of Fr}

Figures 7, 8 and 9 illustrate 3D surface plots of Fr. These figures were drawn according to their mathematical models and using response surface methodology.

\subsection{ANOVA for $\mathrm{Ft}$}

ANOVA results for Ft are indicated in table 7. It can be noted that the depth of cut is the dominant factor affecting tangential cutting force Ft. Its contribution is $77.84 \%$. The second factor influencing $F t$ is feed rate. Its contribution is $16.15 \%$. For cutting speed, its effect is less

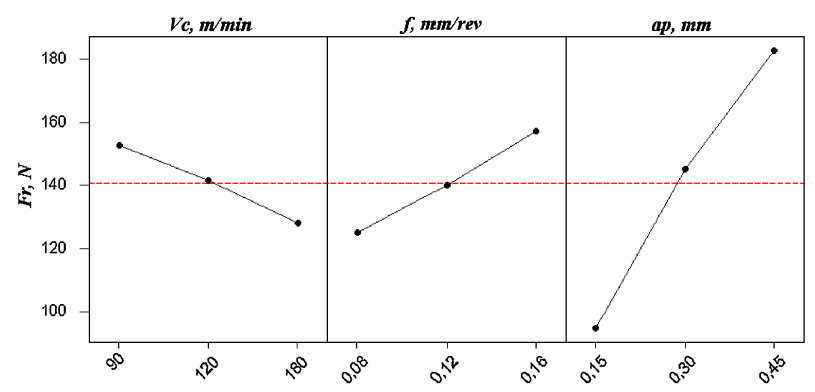

Figure 6. Graphs of the main cutting variables effects on $F r$. 


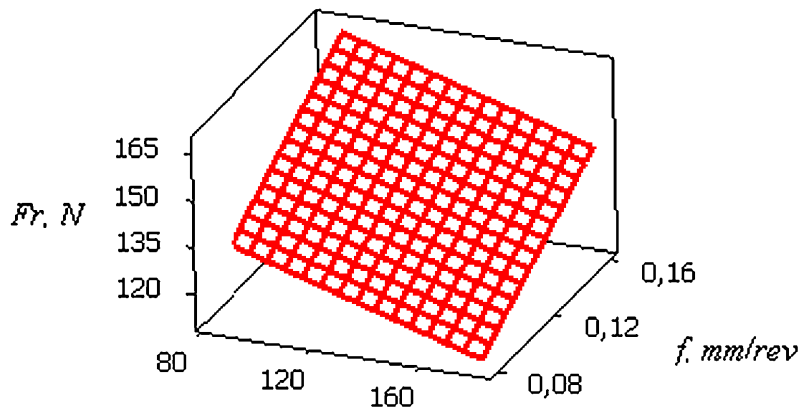

Vc. $m / m i n$

Figure 7. 3D Surface plot of $F r$ vs. $V c$ and $f$.

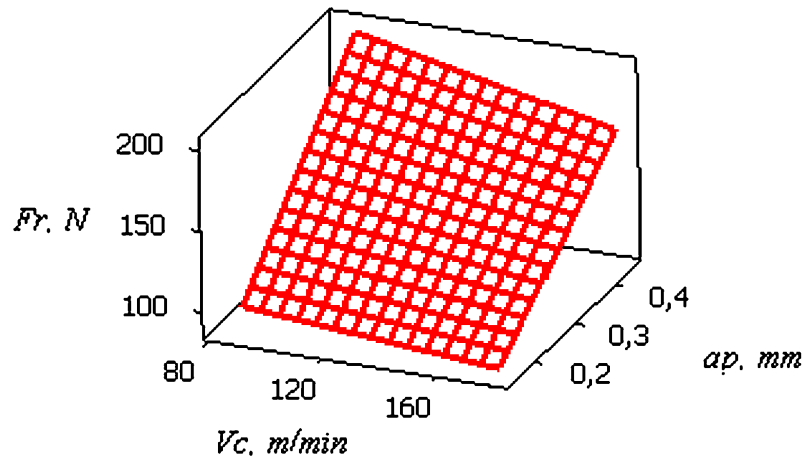

Figure 8. 3D Surface plot of $F r$ vs. $V c$ and $a p$.

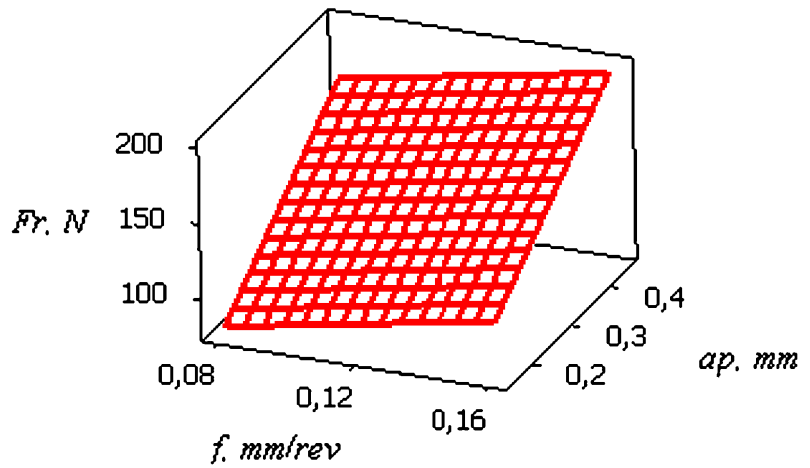

Figure 9. 3D Surface plot of $F r$ vs. $f$ and $a p$. 
Table 7. ANOVA for Ft.

\begin{tabular}{lrrrrrr}
\hline Source & DF & \multicolumn{1}{c}{ SS } & \multicolumn{1}{c}{ MS } & F-VAL. & P-VAL. & Contr. \% \\
\hline$V c$ & 2 & 2821.0 & 1410.5 & 36.83 & $<0.001$ & 3.06 \\
$f$ & 2 & 14893.1 & 7446.5 & 194.46 & $<0.001$ & 16.15 \\
$a p$ & 2 & 71793.2 & 35896.6 & 937.42 & $<0.001$ & 77.84 \\
$V c \times f$ & 4 & 268.4 & 67.1 & 1.75 & 0.231 & 0.29 \\
$V c \times a p$ & 4 & 249.3 & 62.3 & 1.63 & 0.258 & 0.27 \\
$f \times a p$ & 4 & 1898.9 & 474.7 & 12.40 & 0.002 & 2.06 \\
Error & 8 & 306.3 & 38.3 & & & 0.33 \\
Total & 26 & 92230.1 & & & & 100 \\
\hline
\end{tabular}

significant because its contribution is $3.06 \%$. The interaction $f \times a p$ is significant and contribution is $2.06 \%$. The interactions $V c \times f$ and $V c \times a p$ are not significant because their contributions are 0.29 and $0.27 \%$. Ft model is given by equation (3). Its coefficient of correlation $R^{2}$ is $98.3 \%$.

$$
F t=35.21-0.27 V c+119.19 f+183.38 a p+1980.00 f \times a p .
$$

\subsection{Effect graphs of the main cutting regime on Ft}

Figure 10 highlights the main factor plots for $F t$. Tangential cutting force $F t$ appears to be an almost linear decreasing function of $V c$. This figure also indicates that $F t$ is an almost linear increasing function of $a p$ and $f$.

\subsection{D Surface plots for Ft}

Figures 11, 12 and 13 show 3D surface plots for $F t$. These figures were obtained by response surface methodology for different combinations of cutting regime elements according to their mathematical models.

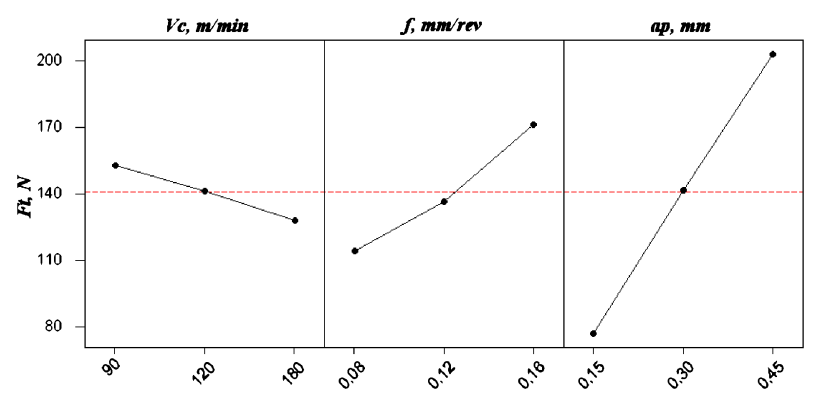

Figure 10. Graphs of the main cutting variables effects on Ft. 


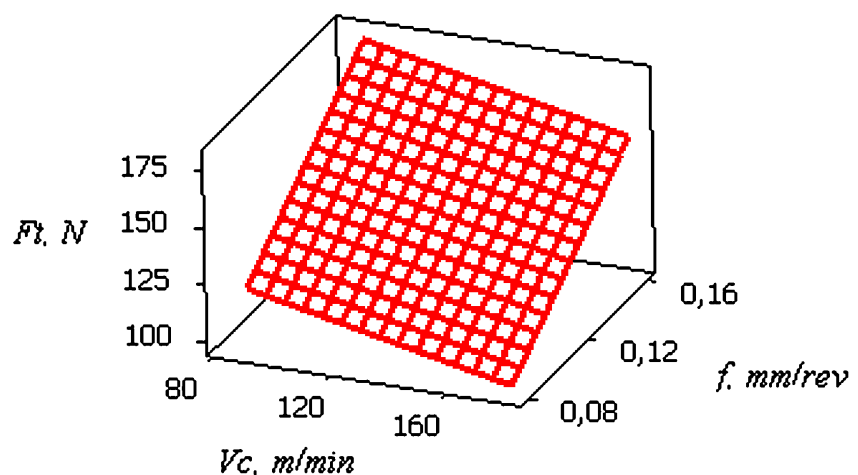

Figure 11. 3D Surface plot of $F t$ vs. $V c$ and $f$.

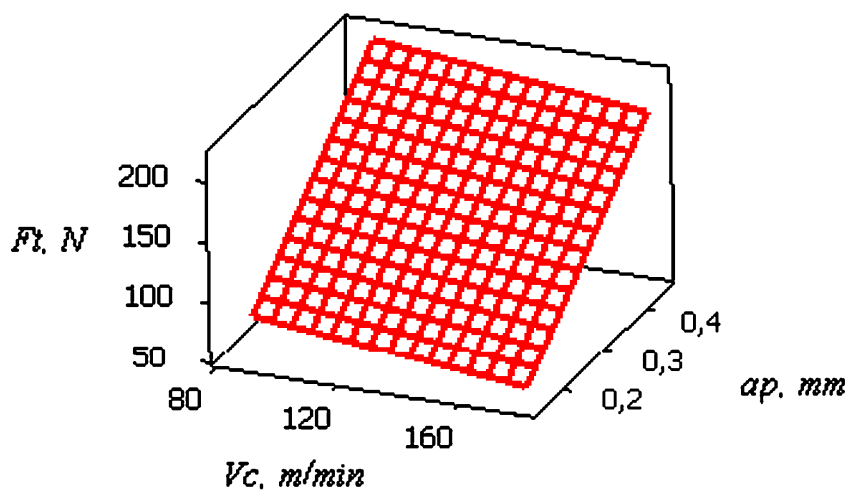

Figure 12. 3D Surface plot of $F t$ vs. $V c$ and $a p$.

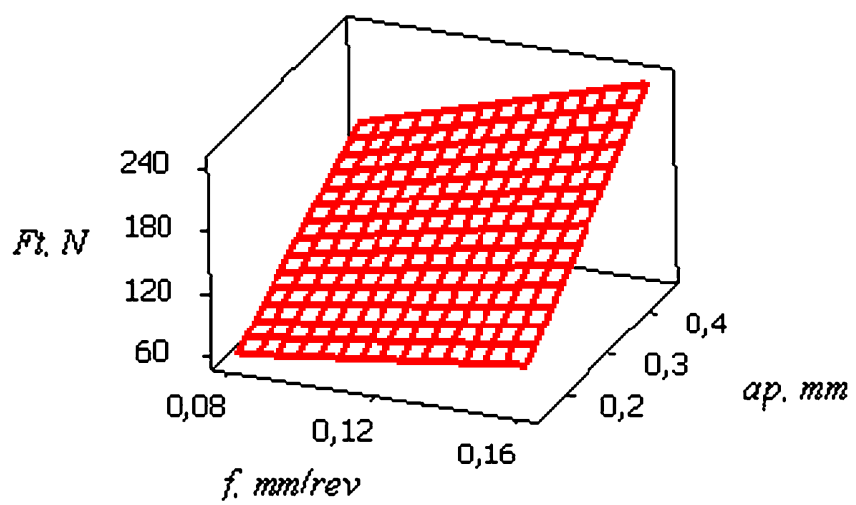

Figure 13. 3D Surface plot of $F t$ vs. $f$ and $a p$. 


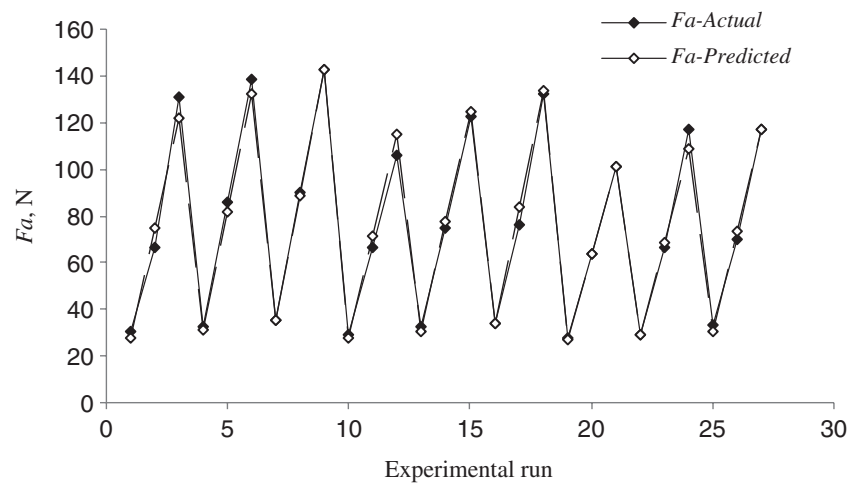

Figure 14. Comparison between measured and predicted values for $\mathrm{Fa}$.

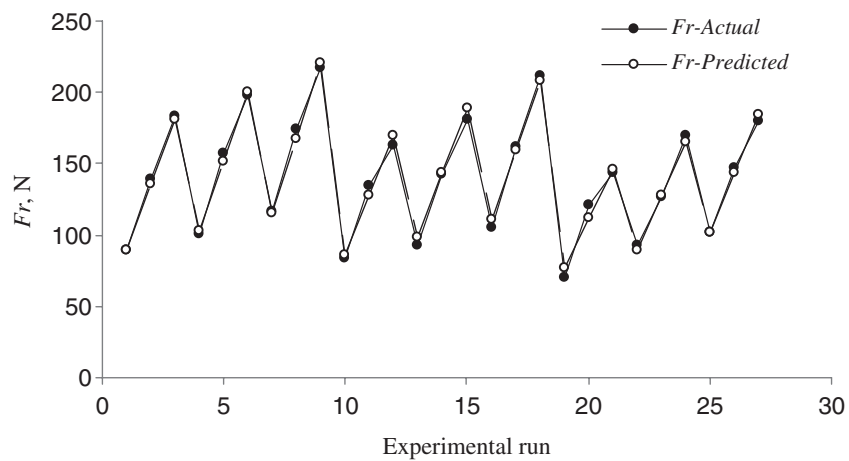

Figure 15. Comparison between measured and predicted values for $\mathrm{Fr}$.

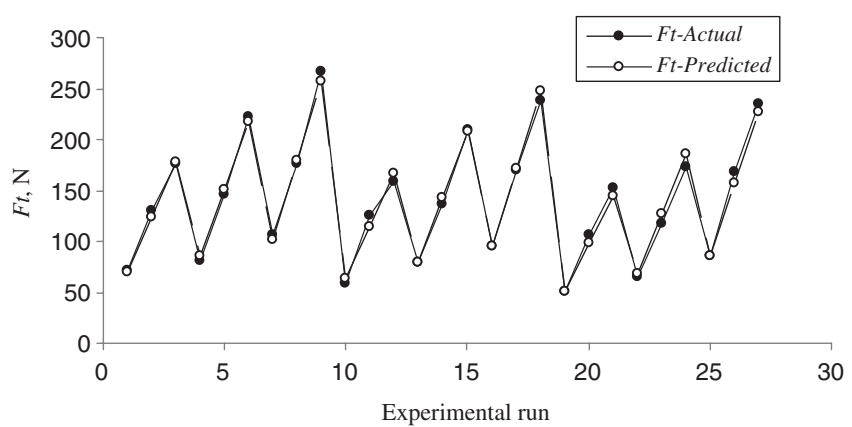

Figure 16. Comparison between measured and predicted values for Ft. 


\section{Confirmation experiments}

The differences between measured and predicted responses are illustrated in figures 14,15 and 16. The results of comparison enabled to predict values of the cutting force components $(\mathrm{Fa}, \mathrm{Fr}$ and $F t$ ) close to those readings recorded experimentally with $95 \%$ confident interval.

\section{Conclusion}

The cutting tests during straight turning carried out on grade AISI H11 steel treated at 50 HRC, with a mixed ceramic tool (insert CC650) enabled us to develop statistical models of cutting force components. These models were obtained by software Minitab using multiple linear regression method and response surface methodology (RSM).

Based on the experimental results, the following conclusions can be drawn:

(i) The depth of cut influences cutting forces in a considerable way. Its contributions on $\mathrm{Fa}, \mathrm{Fr}$ and $F t$ are $94.22 ; 81.14$ and $77.84 \%$, respectively.

(ii) The second factor affecting cutting force is feed rate. Its contributions on $\mathrm{Fa}, \mathrm{Fr}$ and $\mathrm{Ft}$ are $1.72 ; 10.69$ and $16.15 \%$. For cutting speed, its effect is less important.

(iii) This study reveals that in dry hard turning of this steel and for all cutting conditions tested, the principal force is not always the radial force. For this cutting regime $(f=0.16 \mathrm{~mm} / \mathrm{rev}$ and $0.30 \mathrm{~mm} \leq a p \leq 0.45 \mathrm{~mm}$ ), the tangential cutting force becomes the major force followed by radial and axial forces.

(iv) Statistical models deduced defined the degree of influence of each cutting regime element on cutting force components. They can also be used for optimization of the hard cutting process.

(v) Thus, to get good machining system stability, we must use the highest level of cutting speed, $180 \mathrm{~m} / \mathrm{min}$, the lowest level of feed rate, $0.08 \mathrm{~mm} / \mathrm{rev}$ and the lowest level of depth of cut, $0.15 \mathrm{~mm}$.

This work was achieved in the Mechanics and Structures Laboratory (LMS), (University of Guelma, Algeria) in collaboration with LaMCoS (CNRS, INSA-Lyon, France). The authors would like to thank the Algerian Ministry of Higher Education and Scientific Research (MESRS) and the Delegated Ministry for Scientific Research (MDRS) for granting financial support for CNEPRU Research Project, CODE : 0301520090008 (University of Guelma). The authors also would like to express their gratitude to Mr. Ladi Fnides (El-Hadj Mouloud), Mrs. Malika Chiheb Meniai (El-Hadja) and Mr. Hocine Fnides (the artist) for their help.

\section{Nomenclature}

ap Depth of cut, mm

$f \quad$ Feed rate, $\mathrm{mm} / \mathrm{rev}$

$\mathrm{Fa}$ Axial (Feed) force, $\mathrm{N}$

$\mathrm{Fr} \quad$ Radial (Thrust) force, $\mathrm{N}$

Ft Tangential cutting force, $\mathrm{N}$

$H R C$ Rockwell hardness

$R^{2} \quad$ Coefficient of determination

$r_{\varepsilon} \quad$ Tool nose radius, $\mathrm{mm}$

Vc Cutting speed, $\mathrm{m} / \mathrm{min}$ 
$\alpha \quad$ Relief angle, degree

$\gamma \quad$ Rake angle, degree

$\lambda \quad$ Inclination angle, degree

$\chi \quad$ Major cutting edge angle, degree

\section{References}

Abhang L B, Hameedullah M 2010 Chip-tool interface temperature prediction model for turning process. Int. J. Eng. Sci. Technol. 2(4): 382-393

Arsecularatne J A, Zhang L C, Montross C, Mathew P 2006 On machining of hardened AISI D2 steel with PCBN tools. J. Mater. Processing Technol. 171(2): 244-252

Bouacha K, Yallese M A, Mabrouki T, Rigal J-F 2010 Statistical analysis of surface roughness and cutting forces using response surface methodology in hard turning of AISI 52100 bearing steel with CBN tool. Int. J. Refractory Metals and Hard Materials 28: 349-361

Chiang K T 2008 Modelling and analysis of the effects of machining parameters on the performance characteristics in the EDM process of $\mathrm{Al}_{2} \mathrm{O}_{3}+\mathrm{TiC}$ mixed ceramic. Int. J. Adv. Manuf. Technol. 37: 523533

Dewes R C, Aspinwall D K 1997 A review of ultra high speed milling of hardened steels. J. Materials Processing Technol. 69: 1-17

Fnides B, Yallese M A, Aouici H 2008 Hard turning of hot work steel AISI H11: Evaluation of cutting pressures, resulting force and temperature. Mechanika. Kaunas: Technologija, Nr. 4(72): 59-63

Fnides B, Yallese M A, Mabrouki T, Rigal J-F 2009 Surface roughness model in turning hardened hot work steel using mixed ceramic tool. Mechanika. Kaunas: Technologija, Nr. 3(77): 68-73

Gaitonde V N, Karnik S R, Figueira L, Paulo Davim J 2009 Machinability investigations in hard turning of AISI D2 cold work tool steel with conventional and wiper ceramic inserts. Int. J. Refractory Metals and Hard Materials 27: 754-763

Luo S Y, Liao Y S, Tsai Y Y 1999 Wear characteristics in turning high hardness alloy steel by ceramic and CBN tools. J. Materials Processing Technol. 88: 114-121

Noordin M Y, Venkatesh V C, Sharif S, Elting S, Abdullah A 2004 Application of response surface methodology in describing the performance of coated carbide tools when turning AISI 1045 steel. J. Materials Processing Technol. 145: 46-58

Ozel T, Hsu T K, Zeren E 2005 Effects of cutting edge geometry, workpiece hardness, feed rate and cutting speed on surface roughness and forces in finish turning of hardened AISI H13 steel. Int. J. Adv. Manuf. Technol. 25: 262-269

Palanikumar K, Mata F, Paulo Davim J 2008 Analysis of surface roughness parameters in turning of FRP tubes by PCD tool. J. Materials Processing Technol. 204: 469-474

Paulo Davim J, Figueira L 2007 Machinability evaluation in hard turning of cold work tool steel (D2) with ceramic tools using statistical techniques. J. Materials and Design 28: 1186-1191

Qamar S Z 2009 Effect of heat treatment on mechanical properties of H11 tool steel. Journal of Achievements in Mater. and Manufact. Eng. 35/2: 115-120

Sandvik Coromant, 2009 Catalogue Général, Outils de coupe Sandvik Coromant, Tournage - Fraisage Perçage - Alésage - Attachements

Sing D, Venkateswara Rao P 2007 A surface roughness prediction model for hard turning process. Int. J. Adv. Manuf. Technol. 32: 1115-1124

Strafford K N, Audy J 1997 Indirect monitoring of machinability in carbon steels by measurement of cutting forces. J. Mater. Processing Technol. 67(1-3): 150-156

Yallese M A, Chaoui K, Zeghib N, Boulanouar L, Rigal J-F 2009 Hard machining of hardened bearing steel using cubic boron nitride tool. J. Materials Processing Technol. 209: 1092-1104 